Beck J. (Orcid ID: 0000-0002-7387-2307)

\title{
Don't throw the baby teeth out with the bathwater: Estimating subadult age using tooth wear in commingled archaeological assemblages
}

\author{
J. Beck ${ }^{1}$, B.H. Smith ${ }^{2}$ \\ 1. McDonald Institute for Archaeological Research, University of Cambridge, Downing Street \\ Cambridge CB2 3ER, $\mathrm{PhD}$ \\ 2. Museum of Anthropological Archaeology, The University of Michigan, Ann Arbor, MI \\ 48109, USA, PhD
}

Keywords: dental anthropology, subadults, age estimation, tooth wear, commingled, linear regression, $\mathrm{R}$

This is the author manuscript accepted for publication and has undergone full peer review but has not been through the copyediting, typesetting, pagination and proofreading process, which may lead to differences between this version and the Version of Record. Please cite this article as doi: 10.1002/oa.2802

This article is protected by copyright. All rights reserved. 


\begin{abstract}
Commingled assemblages of fragmentary human skeletal remains are a common feature of many archaeological sites and pose significant analytical problems for bioarchaeologists. Such deposits often contain a high volume of the teeth of subadults from which it is challenging to estimate age, including developing permanent teeth with damaged roots, articulated teeth with roots obscured by alveolar bone, and deciduous teeth with completed root apices.

Here, we present a new method for more precisely estimating age for such developmentallyambiguous teeth of subadults from archaeological contexts. We used a sample of articulated subadult dentition from the Copper Age site of Marroquíes in Jaén, Spain, to build linear models of the relationship between dental age and tooth wear for deciduous and permanent molars. We tested three different strategies for identifying and removing outliers to build a linear model with the strongest relationship between age and wear. The Adjusted Residual (AR) strategy, which used diagnostic plots of linear regression residuals in the statistical package $\mathrm{R}$ to identify and remove outliers, was found to produce the strongest linear model. The linear model developed using the AR strategy was then used to provide estimated mid-point ages and upper and lower age bounds based on the wear scores from the sample of developmentally-ambiguous teeth.
\end{abstract}

This study demonstrates that it is possible to estimate the age of developmentally-ambiguous deciduous and permanent molars with reference to an adequate sample of subadult dentition with estimated ages from the same population. This new method is valuable as it extracts information from developmentally-ambiguous teeth that would otherwise be inaccessible, allows for rapid data collection, employs standard macroscopic dental scoring methods, and can be used for sites from other regions and periods. We conclude by discussing the applications of this new method within bioarchaeology and identify directions for future research on subadult dental wear. 


\section{INTRODUCTION}

\subsection{Commingled human remains from archaeological contexts}

The commingling of human bone is a spatially and temporally broad phenomenon and is a form of mortuary assemblage encountered by bioarchaeologists working in many parts of the world (Osterholtz, 2016). Admixtures of human skeletal elements may also incorporate faunal remains or artifacts (Outram et al., 2005), presenting a number of methodological problems for bioarchaeology (Osterholtz et al., 2014). Commingling makes it difficult to associate skeletal elements with specific individuals, particularly when bones are fragmentary or there is a high volume of remains.

Archaeological approaches to such collective deposits often entail detailed mapping of elements in situ, osteological identification and labeling in the field, and a subsequent bioarchaeological analysis which incorporates a high degree of spatial information, minimizing the difficulty in associating elements with individuals (e.g. Lillios et al., 2015; Stodder \& Osterholtz, 2010). However, many existing museum collections were recovered before the advent of modern excavation methods, or as the result of rapid salvage excavations in which detailed mapping of individual elements was not possible. This problem is particularly marked for subadult skeletal remains, as human re-use of mortuary areas and site taphonomy degrade the informative epiphyseal regions typically used to estimate age. Assessments of age using element size, or regression formulae composed from measurements of maximum diaphyseal length are also inadequate when epiphyses and metaphyses are broken or damaged.

In contexts containing a high volume of fragmentary subadult remains, conducting a dental inventory is one strategy that enables the assessment of an entire commingled assemblage, particularly when targeted subsampling is impractical due to complications posed by excavation strategy, recording, or museum curation. As a result of their composition, teeth are less subject to fragmentation than bony elements, and encode important information about age, diet, and dental health (Hillson, 2005). Screening an archaeological assemblage for teeth and associated alveolar 
bone also provides a rigorous means of associating collagen and enamel for radiocarbon dating and isotopic reconstructions of diet and mobility.

\subsection{Developmentally-ambiguous teeth}

Culturally, age is a crucial component of identity, and more precise age estimates can help to unpack the relationship between biological development, understandings of personhood, and cultural rites of passage (Kamp 2001; Tung \& Knudson 2010; Waterman \& Thomas 2011). The two most common strategies for estimating the age of subadults using the dentition are dental eruption (e.g. the passage of teeth from the crypts and eruption through alveolar bone) and dental formation (the stage of development of tooth crowns and roots) (Halcrow et al., 2007). However, these methods cannot be used to estimate age for the teeth of subadults which lack precise developmental indicators due to poor preservation or apex completion of roots. Examples of such "developmentally-ambiguous" teeth include developing permanent teeth with roots that have suffered taphonomic damage, articulated teeth with crown or root formation obscured by alveolar bone, and deciduous teeth with completed root apices that only indicate a minimum age (Table 1).

The period in which apex complete deciduous teeth remain in the mouth stretches from childhood to early adolescence and encompasses significant developmental changes that may have been socially recognized. While a portion of these teeth may be assessed using equipment such as radiography machines or imaging software (e.g. Clement \& Freyne, 2012), such equipment is not readily available in field contexts, and can be expensive and time-consuming for bioarchaeologists to access and implement. Likewise, though Moorrees' et al. (1963a) developed methods for assessing subadult age relative to root resorption of deciduous teeth, these standards were only produced for deciduous mandibular canines, first molars, and second molars, and the original study data were discarded (see Schackelford et al., 2012 for a valiant attempt to reverse engineer the original data). Root resorption criteria are also absent from the most popular bioarchaeological reference texts such as Buikstra \& Ubelaker (1994) or Brothwell (1981), making them less easy to implement broadly. 
The problems posed by developmentally-ambiguous teeth are compounded in prehistoric archaeological assemblages where such elements may comprise a large proportion of the subadult dental sample. The analytical options available often necessitate either (1) categorization of developmentally-ambiguous teeth as simply "subadult" or "probable subadult," obscuring valuable bioarchaeological information about age and personhood, or (2) removal of developmentally-ambiguous teeth from consideration, thereby discarding valuable information about age and minimum number of individuals (MNI) that may be essential for assessments of population size, age structure, and mortuary treatment.

\subsection{The relationship between dental wear and age}

Existing adult aging methods show a tight relationship between the progression of dental wear and age within archaeological samples (Brothwell, 1989; Lovejoy, 1985; Mays, 2002; Miles, 2001; Smith, 1984). Dental wear is age-progressive; enamel does not regenerate once formed and the continued use of the teeth wears away enamel, particularly in occlusal regions (Gilmore \& Grote, 2012). However, the patterning and degree of dental wear are affected by a number of factors, including the abrasiveness of diet and the cultural prevalence of the use of teeth as tools (Brothwell, 1981). While tooth wear thus varies between populations and over time it can be used to provide age-estimates if rates of wear are derived from other individuals drawn from the same chronological and cultural context (Miles, 1962, 1969).

Little research has been conducted that explicitly examines tooth wear patterning in subadults, though existing studies of human deciduous dentition show a relationship between dentine exposure and increasing age (Clement \& Freyne, 2012; Dawson \& Brown, 2013; Skinner, 1997). Given this relationship, subadult dental wear has the potential to provide a method of estimating age for individuals represented by isolated or damaged teeth of subadults in archaeological assemblages.

To test this assertion, we analyzed a fragmentary and commingled assemblage of human remains from the Copper Age site of Marroquíes in Jaén, Spain. First, we screened the 
assemblage for teeth, and identified and scored each tooth for wear. We tested the significance of the relationship between dental age and wear by building linear models using a sample of articulated subadult dentition for which age could be assessed with reference to multiple teeth. We then compared three different strategies for identifying and removing outliers to build stronger models, developing a new method for estimating the age of developmentally-ambiguous teeth of subadults from prehistoric commingled burials.

\section{ARCHAEOLOGICAL CONTEXT OF MARROQUÍES}

The assemblage analyzed is derived from the Copper Age (c. 33250-2200 BC) ditched enclosure of Marroquíes in Jaén, Spain. Here, we focus on Necrópolis 4 (N4), a series of anthropogenic subterranean mortuary caves containing a high volume of commingled and fragmentary human remains. Radiocarbon dates from human bone at N4 indicate a period of mortuary activity between 2720 and 2460 cal BCE (Beck 2016; Díaz-Zorita Bonilla et al., 2018). N4 was most recently excavated in 2001, and all material from these excavations is curated by the Museum of Jaén (Manzano \& Martínez, 2001). Detailed information about the mortuary context of N4 can be found in Beck (2017), Beck et al., (2018), and Díaz-Zorita Bonilla et al., (2018).

\section{MATERIAL AND METHODS}

\subsection{Screening, identification, and wear scoring for all teeth}

The human remains from N4 consisted of $331 \mathrm{~kg}$ of uncleaned and unsorted fragmentary skeletal elements mixed with artifacts and sediment. These materials were screened to recover all loose teeth, articulated teeth, and fragments of alveolar bone with recordable alveoli. Larger skeletal elements were removed before screening the remaining sediment and material using a circular sieve (with apertures measuring $2.5 \mathrm{~mm}$ x $3.5 \mathrm{~mm}$ ). Bone fragments and sediment were hand-sorted on a tray to identify alveolar fragments and teeth. Time constraints made it 
impossible to clean all sediment adhering to human bone, but large cranial fragments with adhering sediment were dry-cleaned or washed to maximize tooth recovery. While this process was tedious and subject to human error, it allowed for the recovery of teeth as small as deciduous central incisors $(\mathrm{N}=12)$ and enamel fragments that could be refit to broken crowns. In total, 3,873 teeth were recovered from the N4 sample, 2,957 (76\%) of which were loose.

Teeth were identified to level of development, tooth category, number, arcade and side (e.g. left lower third molar $\left(\mathrm{LM}_{3}\right)$, right upper deciduous first incisor $\left(\mathrm{rdi}^{1}\right)$ ). Root preservation was scored for all loose teeth to determine the number of teeth for which age assessment was possible (Beck, 2016: 159). Teeth were categorized as "articulated," if more than one tooth was present and associated within the same portion(s) of alveolar bone, or as "loose/single," if a tooth could not be definitively associated with other teeth.

All teeth were scored for wear using the Smith (1984) scoring technique for incisors, canines, and premolars, and the modified Scott (1979) scoring technique for molars, as outlined in Buikstra and Ubelaker (1994:52-53). Methods specific to scoring deciduous tooth wear have previously been developed (Clement \& Freyne, 2012; Dawson \& Brown, 2013; Skinner, 1997). However, the Skinner method is time-consuming to employ as it incorporates four different strategies-photographing dentin exposure, sketching dentin exposure, measuring crown dimensions, and assigning a subjective 'attrition score' - which would prohibitively increase analysis time for a commingled human sample of thousands of loose mixed adult and subadult teeth. Similarly, the Clement \& Freyne (2012) method relies upon the use of image analysis software and is thus time consuming to implement during the data collection process. While Dawson \& Brown (2013) present arguably the most useful scoring method for bioarchaeologists working in commingled contexts, particularly as they provide a visual scoring system comparable to that compiled by Buikstra and Ubelaker (1994: 52-53), their methods have not yet been incorporated into standard bioarchaeological reference texts ${ }^{1}$. In this analysis, we used a

\footnotetext{
${ }^{1}$ Additionally, as this paper was published only six months before the first season of the Marroquíes Bioarchaeological Project, the authors were not aware of its existence during the first round of data collection.
} 
modification of the Smith (1984) guidelines to evaluate deciduous tooth wear, as this is already a widely used standard for scoring adult dentition that most bioarchaeologists are familiar with due to its inclusion in the popular reference manual Standards for Data Collection from Human Skeletal Remains (Buikstra \& Ubelaker, 1994). For deciduous first molars, dental wear was recorded using the Smith guidelines outlined for premolars in Buikstra and Ubelaker (1994: 52), as developmentally the $\mathrm{dm} 1$ is replaced by the P1 and morphologically is more similar to the permanent bicuspids (Figure 1A). Wear for deciduous second molars was recorded using the Scott standards for the permanent molars (Buikstra \& Ubelaker, 1994:53) (Figure 1B). In keeping with the methods employed for estimating age from adult molar wear (Gilmore \& Grote, 2012; Li \& Ji, 1995), dm2 wear was calculated as the average of wear for all observable quadrants.

\subsection{Categorizing teeth as adult or subadult}

For the purposes of this analysis, "subadult" was defined as an individual with an estimated midpoint age of $<18$ years, and "adult" was defined as an individual with an estimated midpoint age of $\geq 18$ years (see section 3.4 for age estimation methods). The teeth of subadults were assessed separately from the teeth of adults, using the categories outlined in Table 2 to divide the sample.

This categorical distinction was made to facilitate the estimation of separate adult and subadult dental MNIs, as an age-stratified subadult dental MNI could incorporate developmental information to increase precision. However, one recognized problem with such a division is that a portion of loose permanent teeth with completed root apices (AlQahtani et al., 2010 stage root $\mathrm{A}_{\mathrm{c}}$ ) may belong to subadult individuals, though this system categorizes them as "adult." This potential miscategorization poses two interrelated analytical problems for dental MNI assessments: overestimating the number of adults present and underestimating the number of subadults present. 
The first problem, overestimation of adult MNI, was explicitly addressed during the calculation of the N4 adult MNI (see Beck 2016: 194-197), but the developmental ambiguity of loose, apex complete permanent teeth, which have the potential to belong to either adults or subadults, remains a significant methodological problem for dental analyses of commingled archaeological samples. The second problem, the underestimation of subadult MNI, remains to be addressed methodologically, but future strategies are suggested in the discussion section of this paper.

\subsection{The subadult dental sample}

The N4 sample contained 787 teeth of subadults (Table 3, Table S1). This included 212 articulated teeth categorized as subadult based on patterning of eruption and tooth development, 266 loose developing permanent teeth, and 73 loose developing deciduous teeth. These $536^{2}$ teeth were aged using the standards provided by the London Atlas, as outlined in section 3.4 (below). The remaining $236(30 \%)$ teeth in the subadult sample were developmentallyambiguous. Developmentally-ambiguous teeth included 82 loose deciduous first and second molars with completed root apices or taphonomic damage which prevented assessment of development, 10 deciduous first and second molars articulated in five fragments of alveolar bone with concealed roots, and 125 deciduous incisors and canines with completed root apices. Finally, an additional sample of 21 teeth in eight separate alveolar fragments were developmentally-ambiguous due to obscured root development and categorized as probable subadult. These probable subadult alveolar fragments contained only erupted permanent teeth, with lightly worn first or first and second molars, and no erupted third molars. With the exception of one first molar with a wear score of $6.25^{3}$, molar wear scores from these probable

\footnotetext{
${ }^{2}$ Fifteen teeth were removed from the sample because their roots or crowns were so damaged that it was not possible to gauge level of development, or they could not be identified to side and thus could not contribute to MNI. ${ }^{3}$ Given the high degree of wear on the first molar from MN.2.177.05, this may represent a case of lower third molar agenesis. In light of the pronounced wear, the two teeth associated with MN.2.177.05 were categorized as an adult, and age was assessed using the adult tooth wear model.
} 
subadult alveolar fragments fell beneath the minimum adult wear score of 3.08 (see Beck, 2016: 214-219). The remaining 19/21 teeth of probable subadults were thus included in the developmentally-ambiguous subadult sample. The newly developed methods outlined in sections 3.5 and 3.6 were used to estimate age for the developmentally-ambiguous teeth of subadults.

\subsection{Assessing subadult dental age using the London Atlas \\ The London Atlas of Tooth Development and Eruption is one of the most recently} developed dental aging standards available and was used as the basis for age assessment in this study (AlQahtani 2009; AlQahtani et al., 2010). The London Atlas presents a visual representation of the sequence of formation and eruption of human teeth, indicating the level of crown formation, degree of root development, and state of eruption for all teeth in the dental arcade for a given age range. These figures are accompanied by summary tables that provide the sample size for each tooth, as well as a minimum, median, and maximum stage of development for teeth. The London Atlas was built using a sex-balanced sample of known age radiographs and known age-at-death skeletons using two groups ("white" and "Bangladeshi") (AlQahtani et al., 2010: 481). It therefore provides a more appropriate reference population for prehistoric European samples than popular alternative standards developed using Native American samples (Ubelaker, 1989) or terminally ill modern reference samples (Schour \& Massler, 1941), The stage ${ }^{4}$ of development of the crown and root, and degree of eruption was scored for each tooth in the Marroquíes subadult sample, using the Moorrees' et al., (1963b) stages employed by AlQahtani et al. (2010). These scores were then used to match teeth to corresponding age categories in the London Atlas. For articulated teeth of subadults, where multiple teeth were present, stage of tooth formation, level of eruption, and developmental relationships between teeth were used to establish the range of assigned age categories possible for the observation, and the midpoint of all assigned age categories was used as the midpoint estimated age. Loose/single

\footnotetext{
${ }^{4}$ In the following description, stage refers to the level of development of the tooth (e.g. Crown initiated, Root complete, etc.), while age category refers to the chronological year (e.g. category 3.5 represents an individual between 3-4 years of age).
} 
teeth of subadults were analyzed with reference to Tables 2-9 in AlQahtani et al. (2010). The age category assigned to each loose/single tooth was the median age listed for its stage of development in AlQahtani et al. (2010). If the developmental stage recorded was the median for more than one age category, the age range estimated for the tooth was extended to cover both age categories, and the tooth was assigned to the middle of those two categories. Articulated teeth were scored for level of development in instances where the bone surrounding sockets had been broken or damaged and revealed tooth roots or patterning in sequence of eruption in instances where more than one tooth was present.

\subsection{Building linear models of the relationship between dental age and tooth wear}

The articulated subadult dental sample for which it was possible to assess age contained 62 alveolar fragments housing 212 articulated teeth of subadults, with between 2-10 teeth per fragment. Age estimates for the articulated subadult sample thus incorporated developmental information from multiple teeth, allowing for a more detailed examination of the patterning of development and eruption for individual observations, producing a more rigorous assessment of age. For these observations it was often possible to record the eruption sequence of multiple teeth or score the level of development of teeth through fragmentary alveolar bone. The articulated sample was used to build linear models of the relationship between dental age and wear in the statistical package R (R Core Team, 2017). The script for all linear models and diagnostic plots is available in an R markdown document provided in Appendix S1, and the data used to build the models are included as a .csv file in Appendix S2.

There were no articulated deciduous incisors or canines in this sample, so linear models of dental age and tooth wear were not developed for the anterior deciduous dentition. For the posterior dentition, including first and second deciduous molars and first and second permanent molars ${ }^{5}$, each linear model was built in two stages. The first stage assessed whether the

\footnotetext{
${ }^{5}$ Deciduous and permanent molars were scored only if they had erupted, and both maxillary and mandibular teeth were incorporated into the model. While Brothwell (1981:72) and Powell (1985: 324) note minor or non-significant
} 
relationship between dental age and wear was significant for the given category of tooth. The second stage examined three different strategies_Adjusted Number, Adjusted Age Range, and Adjusted Residual — for identifying and removing outliers to build a linear model with the strongest possible linear relationship between age and wear.

The Adjusted Number (AN) strategy was developed to assess whether the preservation of a greater number of teeth for a given individual would produce more precise age estimates with narrower age ranges. In order to test this assumption, a regression of age range versus number of teeth was built for the articulated teeth of subadults with estimated age ranges. If there was a significant relationship between the number of articulated teeth and the breadth of estimated age ranges, removing observations with low numbers of teeth could strengthen the linear relationship between tooth wear and dental age. The second approach was an Adjusted Age Range (AAR) strategy, which removed all observations with broad estimated age ranges. In this analysis, a "broad" age range was defined as $\geq$ four years. Finally, the third approach was an Adjusted Residual (AR) strategy. This strategy entailed identifying outliers through the use of the diagnostic plots identifiable for linear regression analysis in $\mathrm{R}$. In base $\mathrm{R}$, the plot (model) command can be used to examine the residuals from a linear regression using four different criteria, which variously examine linearity of patterning, normality of distribution, spread, and leverage (Figure 2, Figure S3-S4). Extreme values for each criterion are identified with reference to their point order in the parent data frame and marked with the point order number on the diagnostic plot. The AR strategy removed all of the extreme values identified by the diagnostic plots. For a concise explanation of diagnostic plots for linear regressions in base R, see Kim (2015).

Once a linear model that maximized the strength of the relationship between dental age and wear was identified, the predict command in $\mathrm{R}$ was employed to estimate the age of teeth

differences in maxillary and mandibular wear rates, combining teeth from both arcades was necessary to produce an acceptable sample size for the regression model for the N4 sample. Additionally, due to the commingled and fragmentary nature of the sample, with a single exception mandibular $(\mathrm{N}=37)$ and maxillary $(\mathrm{N}=24)$ dentition could not be associated, meaning that it was not possible to compare differences in upper versus lower wear rates from the same individual in this study. 
from the developmentally-ambiguous sample based on their wear scores. The predict command produces an estimated mid-point age for each recorded level of wear for the developmentallyambiguous teeth, as well as upper and lower age bounds within a confidence interval specified by the $\mathrm{R}$ user. In this analysis, we elected to use a $95 \%$ confidence interval.

\section{RESULTS}

\subsection{Strength of the relationship between estimated midpoint age and tooth wear for the} subadult articulated sample

Shapiro-Wilks tests revealed that the distribution of wear scores for the $\mathrm{dm} 1, \mathrm{dm} 2$, and M2 samples departed significantly from a normal distribution (Figure S1). However, none of the distributions of residuals from the linear models of age versus wear departed significantly from a normal distribution (Figure S2). In keeping with recent arguments that the distribution of errors is a more useful tool for assessing the normality assumption for linear regressions than the distribution of the dependent variable (e.g. Li et al., 2012), and considering that archaeological sample sizes are often so small that the normality assumption is not met, linear models were treated as an appropriate means of assessing the relationships between estimated midpoint age and tooth wear for these samples.

The linear models showed that there was a significant relationship between wear and dental age for deciduous first molars, deciduous second molars, and permanent first molars in the subadult articulated sample (Figure 3A, 3B, 3C). The relationship between wear and dental age was not significant for the permanent second molars (Figure 3D) (Adjusted $\mathrm{R}^{2}=0.2127, \mathrm{p}=$ 0.639). The deciduous second molars showed the strongest correlation between wear and midpoint estimated age $\left(R^{2}=0.706\right)$, followed by the permanent first molars $\left(R^{2}=0.447\right)$, and the deciduous first molars $\left(\mathrm{R}^{2}=0.259\right)$. As only the sample of permanent first molars showed a significant relationship between estimated midpoint age and wear, linear models of that relationship were created to estimate the age for the sample of developmentally-ambiguous 
"probable subadult" teeth (i.e. the probable subadult alveolar fragments containing only erupted permanent teeth with lightly worn first or first and second molars, $\mathrm{N}=19$ ).

\subsection{Results of comparisons between the linear models (AN, AAR, AR)}

There was no statistically significant relationship between the total number of teeth preserved and the size of the estimated age range in the subadult articulated dental sample (Figure 4) (Adjusted $\mathrm{R}^{2}=-0.01281, \mathrm{p}=0.634$ ). As the number of teeth preserved in an alveolar fragment was not correlated with the breadth of estimated age ranges, it was not possible to identify outliers using the AN method.

Comparing the AAR and AR models revealed that the AAR strategy produced a stronger relationship between estimated age and wear for the deciduous first molars, while the AR models were stronger for both the deciduous second molars and the permanent first molars (Table 4). Both the AAR and AR strategy increased the strength of the relationship between age and wear for the deciduous first and second molars. In contrast, only the AR strategy increased the strength of the relationship between age and wear for the permanent first molars, and the AAR strategy produced a weaker relationship than the initial unadjusted regression for this category of tooth. For both the AAR and AR strategies, the highest $\mathrm{R}^{2}$ values came from the deciduous second molars, followed by the permanent first molars and deciduous first molars, the same pattern identified for the initial linear regressions.

\subsection{Applying the Adjusted Residual model to developmentally-ambiguous teeth}

As the AR strategy increased the strength of the relationship between age and wear for deciduous first molars, deciduous second molars, and permanent first molars, this strategy was used to identify and remove outliers in order to build linear models of age and wear that could be used to estimate the age of the developmentally-ambiguous teeth (Figure 2, Figure S3-S4). These models were then entered into the predict function in base $\mathrm{R}$ to produce age estimates for the 
sample of loose/single developmentally-ambiguous deciduous first molars $(\mathrm{N}=41)$, deciduous second molars $(\mathrm{N}=40)$, articulated deciduous first and second molars with obscured roots $(\mathrm{N}=$ $10)$, and probable subadult alveolar fragments that included lightly worn first molars $(\mathrm{N}=19)$. The AR strategy thus provided age estimates for a sample of 110 teeth of subadults that could not be obtained using conventional age estimation strategies (Table 5). These 110 teeth represent $14 \%$ of the total subadult dental sample from N4.

\section{DISCUSSION}

The development of linear models of the relationship between subadult age and tooth wear has important implications for developing bioarchaeological strategies to more efficiently assess subadult age structure in commingled archaeological assemblages. The results of this analysis suggest that deciduous second molars show the strongest relationship between estimated dental age and wear for subadult posterior dentition. This pattern is likely related to the amount of time that deciduous second molars are present in the mouth. The dm2 is in occlusion for a nine-year window (stages 3.5-11.5), while the $\mathrm{dm} 1$ is only in occlusion for seven years (stages 3.5-10.5) (AlQahtani et al., 2010). As the dm1 erupts at a younger age and is replaced more rapidly than the $\mathrm{dm} 2$, a greater proportion of its tenure in the mouth encompasses the period of breastfeeding and weaning, when diet may not have as strong an effect on wear as later consumption of adult foods. The lack of significant relationship between estimated age and wear for the permanent second molar is also likely related to the shorter time spent erupted in subadults-with only five years erupted and in occlusion, there is less time for wear to accumulate.

What is particularly interesting about these results is that the relationship between age and wear is stronger for deciduous second molars than permanent first molars for all linear models (Figure 3, Figure 5), despite the additional two years the first molars are erupted and in occlusion (stage 6.5 to the study cut off of 17.5 ) relative to the deciduous second molars. The strong correlation between age and wear for the deciduous second molars in the N4 subadult sample also contrasts with the results of Dawson \& Brown, who indicate a more variable relationship 
between age and wear for deciduous second molars in older children (2013: 436). Given that Dawson \& Brown analysed a sample of subadults from late medieval England, a period with different dietary practices and age-related cultural customs than Copper Age Iberia, it is unsurprising that the wear patterns they identify are distinct from this study. Indeed, the known inter-population variability in adult dental wear emphasizes the utility of intra-population assessments of wear rate in order to address this problem in older individuals (Miles 1962; Gilmore \& Grote 2012).

The weaker relationship between age and wear in the AAR linear models for permanent first molars underscores the potential danger inherent in applying broad 'rules of thumb' to identify outliers without careful exploratory data analysis (Figure 5A). Similarly, while this analysis removed all potential extreme values identified by the linear regression diagnostic plots, it is possible to target a subset of these outliers using the diagnostic plots if there is one particular factor-linearity, normality, etc.,- - that one wishes to manipulate in the sample used to build the adjusted linear model.

Though this study demonstrated significant relationships between estimated midpoint age and wear for deciduous first molars, deciduous second molars, and permanent first molars, the relationships between age and wear could not be assessed for the anterior dentition. Deciduous canines and incisors are smaller than deciduous molars, and as single-root teeth are more likely to be found disarticulated in prehistoric assemblages due to taphonomy or the movement of skeletal remains over time. There is thus a particular demand for further research on relationship between age and wear of anterior deciduous teeth in subadult individuals from contexts with better preservation. Studies assessing the relationship between dental age and wear on subadult individuals with an articulated anterior permanent dentition could also help to develop strategies for categorizing permanent root $\mathrm{A}_{\mathrm{c}}$ teeth as either adult or subadult based on level of wear, which is a major problem for categorization of teeth as either adult or subadult in commingled and fragmentary assemblages. Such studies would allow for models of tooth-specific wear rates that could facilitate age assessment of loose fully formed teeth. 
Future studies of the relationship between subadult age and tooth wear will help to elucidate the preliminary patterns revealed in this dataset. While sample sizes for the $\mathrm{dm} 1$ and $\mathrm{dm} 2$ models are above thirty, sample sizes for first and second permanent molars are lower, a factor which may be contributing to the disparities in $\mathrm{R}^{2}$ values for the various models. Expanding sample sizes in future research on the relationship between age and wear in subadult dentition would help to test this hypothesis and would be more likely to produce normally distributed wear data. Using this method with a larger sample of subadults for which both upper and lower jaws could be associated would also allow for comparisons between wear rates for mandibular and maxillary teeth, as previous research has indicated that there are differences in wear rate and arcade for adult teeth (Brothwell, 1981; Powell, 1985). Finally, it is worth noting that the Adjusted Residual model developed here could be used in tandem with wear scoring methods such as those developed by Dawson \& Brown (2013) that are specifically formulated for deciduous dentition. Future projects comparing the results of different deciduous wear scoring methods on the Adjusted Residual strategy will help to refine strategies for age assessment of loose and commingled subadult teeth from archaeological contexts. Finally, assessing the effects of dental anomalies such as malocclusions on patterns of wear in subadult articulated dentition will help to produce more nuanced understandings of variability in the relationship between age and wear for loose teeth.

\section{CONCLUSION}

This paper presents a new method for estimating age for developmentally-ambiguous teeth of subadults from commingled archaeological assemblages. Our sample showed significant relationships between estimated midpoint dental age and wear for deciduous first molars, deciduous second molars, and permanent first molars from the sample of articulated teeth of subadults for which age could be assessed. We present an Adjusted Residual strategy for building linear models to estimate age using wear scores from developmentally-ambiguous teeth. The AR strategy relies on the open-source statistical package $\mathrm{R}$ and existing popular wear scoring 
standards, making it inexpensive and easy to implement. We demonstrate that by building linear models that capture the age-progressive nature of subadult tooth wear, it is possible to extract information on age from teeth which would be otherwise removed from bioarchaeological analysis.

\section{SUPPLEMENTAL MATERIALS}

Supplemental materials, including figures, tables, an R markdown document explaining the script and the raw data as a csv file are available on the repository Zenodo (https://doi.org/10.5281/zenodo.3264936).

\section{ACKNOWLEDGMENTS}

Three anonymous reviewers made suggestions which improved the quality and clarity of the manuscript. Francisca Hornos Mata (Museo de Jaén), Narciso Zafra de la Torre (Consejeria de la Cultura de Jaén), and Pedro Díaz-del-Río provided essential support during data collection, site report access, analysis, and sharing of figures. Ana Manzano Castillo and José Luís Martínez Ocaña were generous with their time, assistance, and access to the documentation of N4. Adam Foster assisted with R, and Zachary Cofran, Erik Gjesfjeld, and Sarah Inskip provided valuable feedback on an early draft of the manuscript. Photographs were taken at the Museo de Jaén and are used with the permission of the Museo de Jaén. This work was supported by a National Science Foundation Doctoral Dissertation Improvement Grant (BCS-1440017), the Ministerio de Economía y Competitividad de España (HAR2013-47776-R), the Consejo Superior de Investigaciones Científicas (CSIC) (2010RU0086), a Marie Skłodowska-Curie European Fellowship (746216), and the University of Michigan. 


\section{REFERENCES}

AlQahtani, SJ. 2009. Atlas of Human Tooth Development and Eruption. Barts and the London School of Medicine and Dentistry, Electronic document, http://www.atlas.dentistry.qmul.ac.uk/, accessed May 31, 2017.

AlQahtani SJ, Hector MP, Liversidge HM. 2010. Brief communication: The London atlas of human tooth development and eruption. American Journal of Physical Anthropology 142: 481490. DOI: 10.1002/ajpa.21258

Beck J. 2016. The Bioarchaeology of Mortuary Practice at Marroquíes Bajos, Spain. Unpublished PhD Dissertation, University of Michigan: Ann Arbor.

Beck J. 2017. Bioarchaeological approaches to social organization at Marroquíes (Jaén, Spain). MENGA: Journal of Andalusian Prehistory 7: 29-50.

Beck J, Díaz-Zorita Bonilla M, Bocherens H, Díaz-del-Río P. 2018. Feeding a third millennium BC mega-site: Bioarchaeological analyses of palaeodiet and dental disease at Marroquíes (Jaén, Spain). Journal of Anthropological Archaeology 52: 23-43. DOI: 10.1016/j.jaa.2018.07.001

Buikstra JE, Ubelaker DH. (eds.). 1994. Standards for Data Collection from Human Skeletal Remains. Arkansas Archaeological Survey Research Series No.44: Fayetteville.

Brothwell DR. 1981. Digging up Bones: The Excavation, Treatment, and Study of Human Skeletal Remains. British Museum: London.

Brothwell, DR. 1989. The relationship of tooth wear to ageing. In Age Markers in the Human Skeleton, Iscan M (ed.). Charles C. Thomas: Springfield; 303-316.

Clement AF, Freyne A. 2012. A revised method for assessing tooth wear in the deciduous dentition. In Proceedings of the Twelfth Annual Conference of the British Association for Biological Anthropology. BAR International Series 2380, Mitchell P, Buckberry J, (eds.). Archaeopress: Oxford; 119-129.

Dawson H, Brown KR. 2013. Exploring the relationship between dental wear and status in late medieval subadults from England. American Journal of Physical Anthropology 150: 433-441. DOI: doi.org/10.1002/ajpa.22221

Díaz-Zorita Bonilla M., Beck J, Bocherens H, Díaz-del-Río P. 2018. Isotopic evidence for mobility at large scale aggregations in Copper Age Iberia. The mega-site of Marroquíes (Jaén). Antiquity, 92, 991-1007. DOI: 10.15184/aqy.2018.33 
Gilmore CC, Grote MN. 2012. Estimating age from adult occlusal wear: A modification of the Miles method. American Journal of Physical Anthropology 149:181-192. DOI:

10.1002/ajpa.22106

Halcrow SE, Tayles N, Buckley HR. 2007. Age estimation of children from prehistoric southeast Asia: Are the dental formation methods used appropriate? Journal of Archaeological Science 34: 1158-1168. DOI: 10.1016/j.jas.2006.10.009

Hillson S. 2005. Teeth. 2nd Ed. Cambridge University Press: New York.

Kamp KA. 2001. Where have all the children gone? The archaeology of childhood. Journal of Archaeological Method and Theory 8:1-34. DOI: 10.1023/A:1009562531188

Kim B. 2015. Understanding diagnostic plots for linear regression analysis. University of Virginia Library. Accessed 11 February 2019: https://data.library.virginia.edu/diagnostic-plots/

Li C, Ji G. 1995. Age estimation from the permanent molar in northeast China by the method of average stage of attrition. Forensic Science International 75:189-196. DOI: 10.1016/03790738(95)01791-7

Li X, Wong W, Lamoureux EL, Wong TY. 2012. Are linear regression techniques appropriate for analysis when the dependent (outcome) variable is not normally distributed? Investigative Ophthalmology \& Visual Science 53: 3082-3083. DOI: 10.1167/iovs.12-9967.

Lillios KT, Waterman AJ, Mack JAA, Artz J, Nilsson-Stutz L. 2015. In Praise of Small Things: Death and Life at the Late Neolithic-Early Bronze Age Burial of Bolores, Portugal. BAR International Series 2716. Archaeopress: Oxford.

Lovejoy CO. 1985. Dental wear in the Libben population: Its functional pattern and role in the determination of adult skeletal age at death. American Journal of Physical Anthropology 68: 4756. DOI: 10.1002/ajpa.1330680105

Manzano Castillo A, Martínez Ocaña J. 2001. Informe de la Intervención Arqueológica en C/ Cristo Rey $N^{\circ}$, de Jaén en Cuevas Artificiales de Marroquíes Altos. Expediente 56/05. Guiomar H.C.M.

Mays S. 2002. The relationship between molar wear and age in an early 19th Century AD archaeological human skeletal series of documented age at death. Journal of Archaeological Science 29: 861-871. DOI: 10.1006/jasc.2001.0751 
Miles AEW. 1962. Assessment of the ages of a population of Anglo-Saxons from their dentitions. Proceedings of the Royal Society of Medicine 5: 881-886.

Miles AEW. 1969. The dentition of the Anglo-Saxons [abridged]. Proceedings of the Royal Society of Medicine 62: 21-25.

Miles AEW. 2001. The Miles method of assessing age from tooth wear revisited. Journal of Archaeological Science 28: 973-982. DOI: 10.1006/jasc.2000.0652

Moorrees CFA, Fanning EE, Hunt EA. 1963a. Formation and resorption of three deciduous teeth in children. American Journal of Physical Anthropology 21: 205-213.

Moorrees CFA, Fanning EE, Hunt EA. 1963b. Age variation of formation stages for ten permanent teeth. Journal of Dental Research 42: 1490-1502.

Osterholtz AJ. (Ed.). 2016. Theoretical Approaches to the Analysis and Interpretation of Commingled Human Remains. Springer: Cham. DOI: 10.1007/978-3-319-22554-8

Osterholtz AJ, Baustian KM, Martin DL. (eds). 2014. Commingled and Disarticulated Human Remains: Working Toward Improved Theory, Method, and Data. Springer: New York. DOI: 10.1007/978-1-4614-7560-6

Outram AK, Knüsel CJ, Knight S, Harding AF. 2005. Understanding complex fragmented assemblages of human and animal remains: a fully integrated approach. Journal of Archaeological Science 32: 1699-1710. DOI: 10.1016/j.jas.2005.05.008.

Powell ML. 1985. The a nalysis of dent al wear and caries for diet ary reconstruction. In The Anal ysis of Prehist oric Diet s, Gil ber t RI, Miel ke JH (eds.). Ac a demic Press: Or 1 ando; 307- 338.

R Core Team. 2017. R: A language and environment for statistical computing. R Foundation for Statistical Computing, Vienna, Austria. Accessed 23 April 2019 https://www.R-project.org/.

Scott EC. 1979. Dental wear scoring technique. American Journal of Physical Anthropology 51: 213-218. DOI: doi.org/10.1002/ajpa.1330510208

Schour I, Massler M. 1941. The development of the human dentition. Journal of the American Dental Association 28: 1153-1160. 
Shackelford LL, Stinespring Harris AE, Konigsberg LW. 2012. Estimating the distribution of probable age-at-death from dental remains of immature human fossils. American Journal of Physical Anthropology 147: 227-253. DOI: 10.1002/ajpa.21639

Skinner, Mark. 1997. Dental wear in immature Late Pleistocene European hominines. Journal of Archaeological Science 24: 677-700. DOI: 10.1006/jasc.1996.0151

Smith BH. 1984. Patterns of molar wear in hunter-gatherers and agriculturalists. American Journal of Physical Anthropology 63: 39-56. DOI: doi.org/10.1002/ajpa.1330630107

Stodder ALW, Osterholtz AJ. 2010. Analysis of the processed human remains from the Sacred Ridge site: Methods and data collection protocol. In Animas-La Plata Project. Vo. XVBioarchaeology, Perry E, Stodder A, Bollong C, (eds.). SWCA Anthropological Research Paper No. 10: 243-278.

Tung TA, Knudson KJ. 2010. Childhood lost: Abductions, sacrifice, and trophy heads of children in the Wari. Latin American Antiquity 21: 44-66. DOI: 10.7183/1045-6635.21.1.44

Ubelaker DJ. 1989. Human Skeletal Remains: Excavation, Analysis, Interpretation. $2^{\text {nd }}$ Ed. Taraxacum: Washington.

Waterman AJ, Thomas JT. 2011. When the bough breaks: Childhood mortality and burial practice in Late Neolithic Atlantic Europe. Oxford Journal of Archaeology 30: 165-183. DOI: 10.1111/j.1468-0092.2011.00363.x

\section{FIGURE CAPTIONS:}

Figure 1. Sample wear scoring for (A) deciduous first molars and (B) deciduous second molars, with wear scores $(\mathrm{dm} 1)$ or average wear scores $(\mathrm{dm} 2)$ bolded beneath each photograph. All teeth are from the right mandibular arcade, positioned in occlusal view, with the mesial side of the tooth oriented towards the top of the page. Individual quadrant scores are shown around the perimeters of the deciduous second molars, with total wear scores shown beneath them. Written descriptions are excerpted from Buikstra and Ubelaker (1994: 52-53), and more detailed descriptions may be found in that reference.

Figure 2. Diagnostic plots for the $\mathrm{dm} 2$ linear model $(\mathrm{N}=35)$. Outliers are identified using numbers (in this case, $4,44,53$, and 58), which specify their row order in the original data file (found under column "Point_Order" in Appendix S2). In this case, the fourth, forty-fourth, fiftythird, and fifty-eighth row in the spreadsheet are outliers. 
Figure 3. Linear regression of the relationship between average permanent molar wear and midpoint age for subadult articulated sample. Points jittered in ggplot 2 to avoid overlap and display full size of sample. Slopes for $\mathrm{dm} 1, \mathrm{dm} 2$, and M1 significantly different from zero at $\mathrm{p}<0.005$; slope for M2 not significant different from zero, $\mathrm{p}=0.639$.

Figure 4. Relationship between number of teeth (x) and breadth of age range (y) in the sample of articulated subadult dentition from Necropolis 4. Points jittered in ggplot 2 to avoid overlap and display full size of sample. Slope of line does not differ significantly from zero, $p=0.6269$.

Figure 5. Comparison of Adjusted Age Range (left column) and Adjusted Residual (right column) linear models of the relationship between wear score and dental age for deciduous molars and permanent first molars (both sides and arcades) from the subadult articulated sample. Points jittered in ggplot 2 to avoid overlap and display full size of sample. All slopes significantly different from zero at $\mathrm{p}<0.005$. 

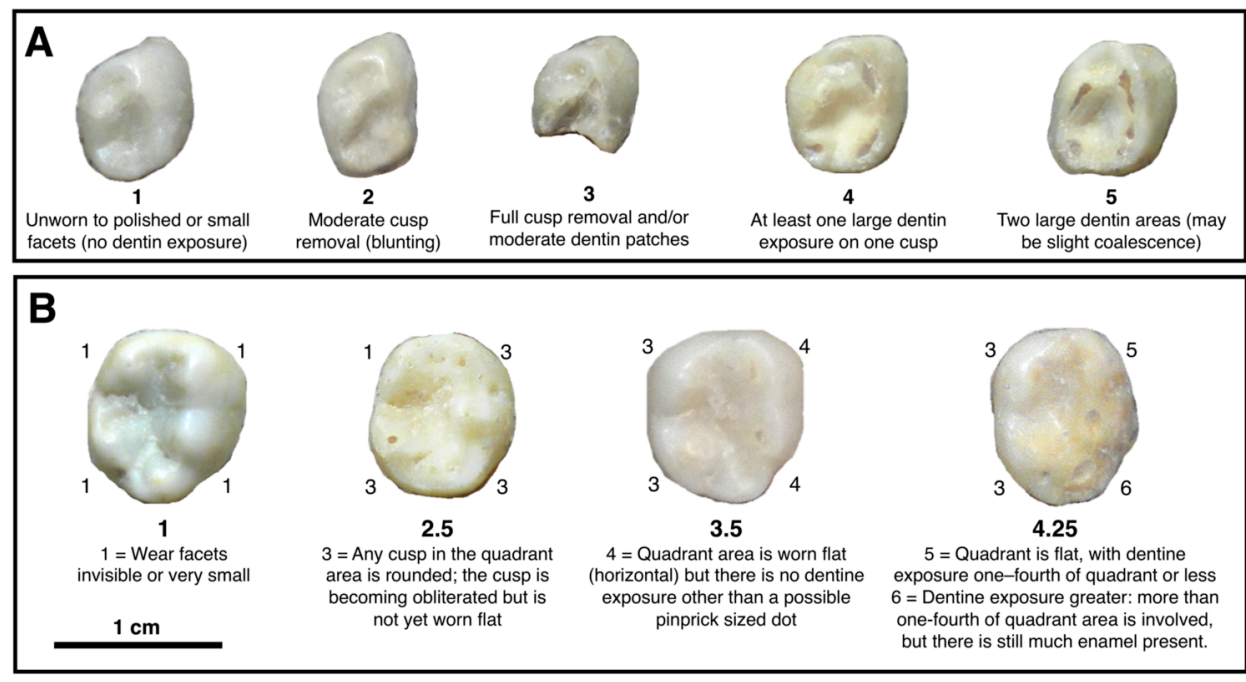

OA_2802_Figure 1 .tiff

This article is protected by copyright. All rights reserved. 

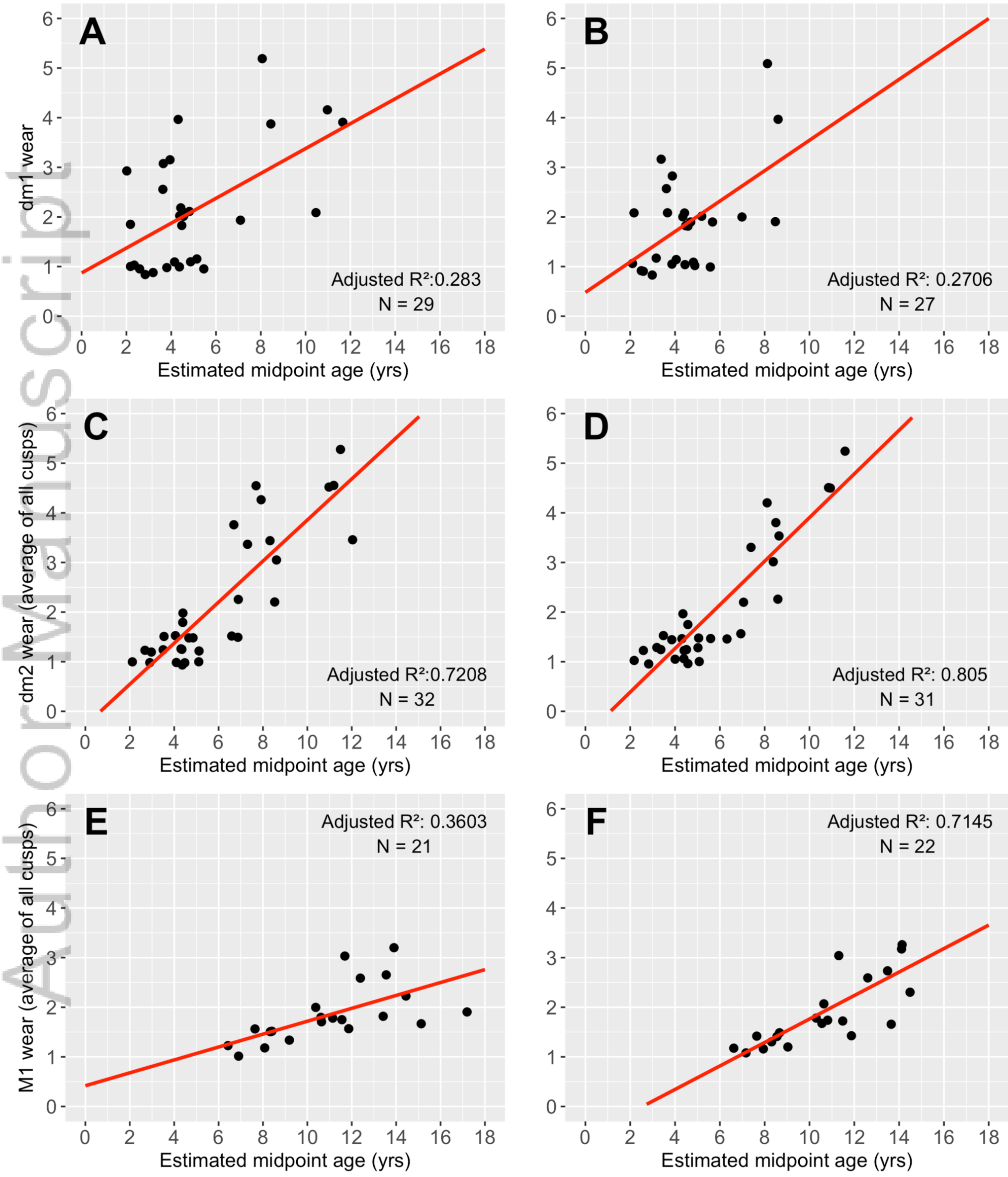

OA_2802_Figure 5.png

This article is protected by copyright. All rights reserved. 


\section{FIGURES}

Figure 1. Sample wear scoring for (A) deciduous first molars and (B) deciduous second molars, with wear scores $(\mathrm{dm} 1)$ or average wear scores $(\mathrm{dm} 2)$ bolded beneath each photograph. All teeth are from the right mandibular arcade, positioned in occlusal view, with the mesial side of the tooth oriented towards the top of the page. Individual quadrant scores are shown around the perimeters of the deciduous second molars, with total wear scores shown beneath them. Written descriptions are excerpted from Buikstra and Ubelaker (1994: 52-53), and more detailed descriptions may be found in that reference.

Figure 2. Diagnostic plots for the $\mathrm{dm} 2$ linear model $(\mathrm{N}=35)$. Outliers are identified using numbers (in this case, 4, 44, 53, and 58), which specify their row order in the original data file (found under column "Point_Order" in Appendix S2). In this case, the fourth, forty-fourth, fiftythird, and fifty-eighth row in the spreadsheet are outliers.

Figure 3. Linear regression of the relationship between average permanent molar wear and midpoint age for subadult articulated sample. Points jittered in ggplot 2 to avoid overlap and display full size of sample. Slopes for $\mathrm{dm} 1, \mathrm{dm} 2$, and M1 significantly different from zero at $\mathrm{p}<0.005$; slope for M2 not significant different from zero, $\mathrm{p}=0.639$.

Figure 4. Relationship between number of teeth (x) and breadth of age range (y) in the sample of articulated subadult dentition from Necropolis 4. Points jittered in ggplot 2 to avoid overlap and display full size of sample. Slope of line does not differ significantly from zero, $\mathrm{p}=0.6269$.

Figure 5. Comparison of Adjusted Age Range (left column) and Adjusted Residual (right column) linear models of the relationship between wear score and dental age for deciduous molars and permanent first molars (both sides and arcades) from the subadult articulated sample. Points jittered in ggplot 2 to avoid overlap and display full size of sample. All slopes significantly different from zero at $\mathrm{p}<0.005$. 